\title{
O Fast Fashion e a identidade de marca
}

\author{
Fast Fashion and brand identity
}

\author{
SHIMAMURA, Erica; Especialista; \\ Universidade Estadual de Londrina \\ erica.shimamura@gmail.com
}
SANCHES, Maria Celeste de Fátima; Doutoranda pela Faculdade de Arquitetura e Urbanismo da Universidade Estadual de São Paulo;
Universidade Estadual de Londrina;
tsanches@sercomtel.com.br

\begin{abstract}
RESUMO
Este artigo foi desenvolvido com o propósito de compreender o fenômeno fast fashion, as razões para o seu sucesso e de que maneira as empresas do setor estabelecem identidade de marca perante seus consumidores. Para alcançar o objetivo proposto, foi realizada uma revisão bibliográfica e a análise comparativa entre os parâmetros que norteiam tal fenômeno e as diretrizes para a construção de identidade de marca. Como resultado, foi demonstrado que as empresas do segmento apresentam potencial para aderir a um processo de construção de identidade de marca, a exemplo da empresa espanhola Zara, que elegeu a comunicação como ferramenta fundamental para estabelecer vínculo com seus consumidores e compor sua identidade de marca.
\end{abstract}

Palavras-chave: Fast fashion; Identidade de marca; Consumo.

\begin{abstract}
This article was developed with the purpose of understanding the fast fashion phenomenon, the reasons for its success and how the sector companies establish brand identity towards its consumers. To achieve our objective, we conducted a literature review and comparative analysis of the parameters that govern this phenomenon and guidelines for building brand identity. As a result, it was shown that the firms in this sector have potential to join a process of building brand identity, such as the spanish firm Zara, which has made communication a key tool in order to establish ties with their customers and develop its brand identity.
\end{abstract}

Keywords: Fast fashion; Brand identity; Consumption.

\section{INTRODUÇÃO}

O sucesso das empresas de fast fashion, observado nos últimos anos, aponta para uma mudança importante no padrão de consumo da atualidade, tanto no mercado nacional quanto no contexto internacional. E também nos revela o quanto a indústria da moda está transformando rapidamente os seus modelos de atuação.

Atendendo a uma demanda mundial de consumidores cada vez mais vorazes em investir tempo e renda na compra de artigos de vestuário, o fast fashion é um sistema que cresce em faturamento e prestígio graças à velocidade com que consegue responder aos anseios de um público mais exigente que no passado, habituado às compras por impulso, acostumado às constantes mudanças sociais e preocupado em satisfazer suas necessidades individuais de consumo e prazer.

A troca de mercadorias nas redes de fast fashion acontece com uma rapidez nunca antes observada, chegando a ser realizada até mesmo semanalmente. No entanto, a velocidade não é a 
única característica capaz de resumir este fenômeno da moda. Seguindo um modelo organizativo mais adequado aos novos tempos, o fast fashion apresenta grande capacidade de minimizar riscos e custos das coleções, de otimizar a gestão do processo criativo e de tornar flexível a cadeia de produção.

O modelo adotado pelas principais empresas do setor visa atingir públicos amplos, por meio de um mix de produtos em que se misturam peças semi-exclusivas e linhas básicas. As roupas produzidas no âmbito da moda rápida são conhecidas pelo design atualizado a preços acessíveis, porém também são associadas à baixa qualidade dos materiais e dos acabamentos, por isso receberam o rótulo de 'moda descartável'. Na cadeia de produção, essas empresas são alvo de constantes críticas, principalmente por meio de reportagens que denunciam a exploração de fornecedores terceirizados, que precisam cumprir preços e condições de prazo que levam à exploração da mão de obra.

No entanto, algumas empresas do setor, como a Zara, estão concentrando sua produção em países da Europa, e não na China e na Índia, como ocorre com a maioria de seus concorrentes. Segundo Rogar (2012), cerca de 65\% do total da produção da Zara é feita na Europa, em paises como Portugal, Espanha, Turquia, Romênia e Bulgária. Na América do Sul, o Brasil é o principal produtor de roupas da marca, completando o abastecimento da rede no cone Sul do planeta.

Em relação à inovação, na visão das marcas tradicionais, o sistema da moda rápida pouco tem de criativo, já que seus produtos são lançados, em muitos casos, com muita similaridade às peças observadas nas coleções apresentadas em desfiles e feiras de moda.

No entanto, Cietta (2010) argumenta que tal similaridade se explica pelo modo de funcionamento do modelo fast fashion, que no prazo de poucas semanas consegue lançar uma coleção e colocá-la no mercado, diferentemente do que ocorre com a moda programada tradicional, que desde a escolha das tendências e das matérias-primas até a venda do vestuário nas lojas precisa de um tempo de aproximadamente 24 meses. Ou seja, o sistema fast fashion é capaz de projetar e produzir roupas com muita rapidez, no período em que as tendências de consumo atingem seu auge, o que acaba resultando em produtos semelhantes aos lançados pelas grifes do sistema tradicional.

Independentemente das discordâncias acerca deste sistema, sua relevância no mercado mundial de moda é incontestável, evidenciando a importância de pesquisas que se destinam a compreendê-lo. Neste sentido, este artigo se propõe a discutir a construção de identidades de marca dentro do sistema fast fashion, na tentativa de descobrir em que medida é possível desenvolver uma identidade forte e consolidada diante deste modelo de negócio em que a velocidade acelerada é constante, desde a captação das tendências de consumo até a chegada do produto às lojas.

Para iniciar esta reflexão, é necessário, antes de mais nada, determinar uma distinção conceitual a respeito do termo fast fashion, e apontar de que forma o contexto histórico facilitou a instalação e o florescimento deste sistema de moda, sobretudo no final da década de 1990, época em que as grandes empresas pioneiras do setor encontraram terreno fértil para ganhar os mercados mundiais.

\section{Aceleração do consumo: contexto histórico}

A aceleração do ciclo de consumo no Ocidente não aconteceu repentinamente. Partindo do pressuposto de que cultura e consumo estão intimamente ligados, é preciso considerar as transformações ocorridas dentro da sociedade para facilitar a compreensão dos fatores que imprimiram força ao crescimento do consumo.

De acordo com McCracken (2003), a Inglaterra presenciou um boom de consumo no século 16, mais precisamente nos últimos 25 anos do referido século. Reconstruindo sítios no campo, em modelos grandiosos, os nobres elizabetanos começaram a assumir também as despesas de manter uma residência em Londres. Segundo o autor, esses nobres entretinham-se uns aos outros, bem como a seus subordinados e à sua monarca, às expensas de um gasto arruinador.

Durante o reinado de Elizabeth I, o surto de gastos foi utilizado como instrumento de governo. A monarca aprendeu a utilizar o consumo como uma maneira de criar um "amplo teatro dedicado ao engrandecimento de seu poder, e ainda como um mecanismo de empobrecimento de seus súditos potencialmente detentores de poder em demasia" (MCCRACKEN, 2003: 35).

A competição social entre os membros da nobreza também foi um fator de explosão do 
consumo no século 16.

Quando o nobre se dirigia à corte, acabava se afastando de sua localidade no campo. Em Londres, este mesmo nobre tornava-se apenas um indivíduo a mais na disputa pela proeminência. Assim, sua reação era se deixar levar por um excesso de consumo para se destacar na multidão de "buscadores-de-status" (MCCRACKEN, 2003: 31).

Tais mudanças tiveram implicações sobre o consumo na história da Inglaterra. O consumo familiar, que antes era um assunto coletivo, muda seu caráter. A partir daí, o nobre elizabetano começou a gastar mais para si e menos pela família. A conseqüência foi o enfraquecimento do contrato recíproco que unia a família, transformando também a dinâmica da tomada de decisões quanto ao consumo, que de coletiva passou a ser individual.

Tradicionalmente, os bens eram considerados mais valiosos à medida que se tornavam mais antigos, isto é, "capazes de adquirir um aspecto de pátina e de sobreviver por várias gerações de propriedade familiar, representando riquezas há muito estabelecidas e de ancestrais distintos" (MCCRACKEN, 2003: 32).

No entanto, o nobre elizabetano, levado a Londres e movido por novas ansiedades, passa a gastar mais para si e menos pela corporação familiar, implicando, entre outros aspectos, na mudança da natureza dos bens de consumo. Comprados em função de demandas imediatas de uma guerra social, os bens passaram a assumir novas qualidades. Assim, não eram mais produzidos com a preocupação da longevidade, deixando ao mesmo tempo de serem valiosos pela antiguidade.

Para McCracken (2003), essas mudanças ajudaram a dar início a uma transformação nas propriedades simbólicas dos bens de consumo, levando à mudança do sistema pátina para o sistema moda, em que os novos bens, adquiridos e substituídos com maior freqüência, passam a conferir status social.

Por conseguinte, o século 18 foi considerado o período que viu o nascimento da sociedade de consumo. Na época, o mundo dos bens se expandiu e incluiu novas oportunidades de compras, seja em móveis, cerâmicas, pratas ou tecidos. A freqüência com que os artigos eram consumidos também aumentou, além do número de pessoas que consumiam. A participação das classes subordinadas no consumo marca o período, graças à prosperidade vivida na Inglaterra durante o referido século.

Durante o século 19 não houve boom de consumo. "A revolução do consumo, neste momento, já havia se instalado como uma característica estrutural da vida social (...) era um fato social permanente" (MCCRACKEN, 2003: 43). Segundo o autor, as exposições de Paris de 1889 e 1900 foram os primeiros meios planejados de consumo de massa, e que devido a isso, deram contribuições decisivas no desenvolvimento da loja de departamento e das feiras de negócios.

$\mathrm{Na}$ loja de departamento, os consumidores eram encorajados a passear pelos ambientes à vontade, absorvendo suas fantásticas representações de mundos exóticos e de bens de consumo (...) O objetivo retórico do mercado havia mudado. Este dedicava-se agora a despertar o desejo livremente oscilante, ao invés de meramente incentivar a compra de itens específicos (WILLIAMS, 1982: 67, apud MCCRACKEN, 2003: 47).

Ao longo do século 20, a diversificação da oferta de bens de consumo em diversos segmentos foi ampliada. No campo da moda, essa diversificação de produtos também ganhou dimensão maior. Para Delgado (2008), a aceleração da oferta de artigos ajudou a modificar a relação entre produtos e indivíduos.

Assim, os artigos de vestuário que antes eram utilizados como forma de disputar status social, aos poucos, vão se convertendo em símbolos que representam culturalmente os indivíduos (...) O estilo dos objetos que consumimos será um reflexo da forma como nos comportamos e pensamos a sociedade em que vivemos (DELGADO, 2008: 4). 
Sobretudo a partir das décadas de 1950 e 1960, a grande referência para a moda passa a ser o jovem e seu universo, o qual atuava como formador de opinião. Assim, a alta costura deixa de ditar as tendências no campo da moda.

No fim da década de 1950, a alta costura, cujos resultados pioram a cada estação, entrevê mais uma vez os limites de seu desenvolvimento. Essa constatação tem por efeito estimular os costureiros que vão inovar em um campo até então inexplorado, o prêt-à-porter dos costureiros (GRUMBACH, 2009: 229).

Entre 1966 e 1967, o número de casas da alta costura passa de 39 para 17. A partir daí, o faturamento da casas mais famosas decai de forma irreversível.

O sistema anterior caracterizava-se por uma forte homogeneidade de gosto, pela existência de tendências anuais relativamente unificadas, devido à proeminência da alta costura (...) Ao longo dos anos 1960 e 1970, esse consenso estético foi pulverizado com o impulso do sportwear, das modas jovens marginais, dos criadores do prêt-à-porter (...) Já não há uma moda; há modas (LIPOVETSKY, 1989:124).

Com a globalização da economia e das comunicações, fenômeno vivenciado a partir das décadas de 1980 e 1990, a oferta de produtos tomou proporções gigantescas. Simultaneamente a essas transformações, verificou-se uma grande segmentação dos mercados, especialmente no campo da moda. Para Delgado (2008), a aceleração da velocidade na difusão de informações sobre moda teve como conseqüência uma maior divulgação e produção de novas tendências de consumo.

Pelo viés sociológico, a sociedade contemporânea vive a era da hipermodernidade, período posterior à pós-modernidade. Hoje, a velocidade acelerada atinge todas as esferas da vida, desde o trabalho até as atividades cotidianas mais triviais. Dessa forma, o novo ritmo de vida que se impõe acaba atingindo também a maneira de consumir. Na abordagem de Lipovetsky (2004), o que antes era visto como consumismo, na hipermodernidade torna-se uma realidade para um número muito maior de pessoas.

O que nutre a escala consumista é indubitavelmente tanto a angústia existencial quanto o prazer associado às mudanças, o desejo de intensificar o cotidiano. Talvez esteja aí o desejo fundamental do consumidor hipermoderno: renovar a sua vivência do tempo, revificá-la por meio de novidades que se oferecem como simulacros de aventura (...) Na fúria consumista, exprime-se a recusa ao tempo exaurido e repetitivo, um combate contra esse envelhecimento das sensações que acompanha a rotina diária (LIPOVETSKY, 2004: 80 ).

Nesse contexto, as empresas de fast fashion encontraram terreno fértil para conquistar o sucesso no mercado altamente competitivo atual. Graças à capacidade de oferecer roupas com design atualizado, a preços acessíveis, em escala mundial, essas empresas alcançaram notoriedade e altas taxas de rentabilidade.

Segundo Cietta (2010), o grande trunfo do modelo fast fashion está na capacidade de oferecer em prazos muito curtos aquilo que o mercado premia, abastecendo as lojas constantemente com artigos projetados em cima das tendências de consumo. Dessa maneira, esse sistema consegue gerenciar melhor o risco inerente ao lançamento de uma coleção, diminuindo as chances de os artigos não serem vendidos.

Assim, é possível relacionar os novos hábitos de consumo ao crescimento das empresas de fast fashion, tendo em vista que nas lojas do segmento os produtos são repostos semanalmente, ignorando o calendário tradicional da moda, baseado na virada das estações do ano. Caetano (2011) acredita que atualmente já se pode falar em um novo calendário para a moda. Para a autora, os consumidores do século 21 preferem adquirir novos produtos de moda como se existissem dez ou mais estações 
diferentes em um único ano, demandando das marcas novas criações.

\section{O fast fashion}

Em termos gerais, trata-se de um sucesso entre os sistemas da moda na atualidade. $O$ fenômeno fast fashion, mesmo não sendo uma novidade absoluta para o setor, chama a atenção pela alta rentabilidade que alcançou e pela expansão contínua das empresas que adotaram tal modelo desde o final da década de 1990.

De acordo com Cietta (2010), o número de empresas que alcançou os modelos organizativos e de estratégia do fast fashion está aumentando, e estas adquirem cada vez mais espaço no mercado.

Para Cietta (2010), é imprescindível tentar compreender em quais aspectos as empresas do fast fashion são realmente inovadoras, tendo em vista que, há dez anos, algumas companhias italianas dos distritos de Capri e de Prato já trabalhavam com lógicas semelhantes, porém, sem obterem progressos empresariais semelhantes.

A Zara, marca espanhola do Grupo Inditex, é um dos maiores conglomerados de moda fast fashion no mundo. A companhia tinha por volta de 500 pontos de venda em meados da década de 1990, sendo mais de três quartos localizados na Espanha. Em 2008, indica Cietta (2010), as lojas do grupo estavam presentes em 68 países, com cerca de 3.700 pontos de venda. Hoje, a Zara contabiliza 5.500 lojas no mundo. No Brasil, a marca está presente há 13 anos e conta com 32 endereços.

Na Europa, afirma Cietta (2010), pode-se dizer que o modelo de negócios fast fashion representa uma tendência. Um estudo da Bain\&Co revelou o crescimento do sistema de moda rápida e as características de cada mercado: a Espanha lidera com uma fatia de cerca de $20 \%$ do mercado, seguida pelo Reino Unido, que detém $12 \%$ da cota. Na França, a fatia é de $8 \%$, enquanto que na Alemanha é de $5 \%$. Já a Itália apresenta um mercado de $20 \%$, considerando a produção das empresas italianas mais voltadas às multimarcas de cadeias internacionais como Zara e H\&M e as italianas Oviesse Industry, Motivi e o Grupo Miroglio.

A grande capacidade de interpretar as tendências de consumo e oferecer em prazos curtos aquilo que o mercado premia é algo que deve ser considerado como ponto relevante no setor do fast fashion. Na opinião de Cietta (2010), o sistema faz sucesso pela sua velocidade de resposta ao público consumidor, já que consegue produzir artigos de vestuário de um modo extremamente veloz, chegando a lançar coleções no prazo de poucas semanas, quando as tendências encontram-se em seu auge, diferentemente do modelo tradicional de produção, que trabalha com uma antecipação de 24 meses para lançar novos produtos no mercado.

A rapidez é, de fato, parte importante deste sistema, mas não é a única característica predominante capaz de determinar seu sucesso. Para entender o fast fashion, lembra Cietta (2010), é preciso analisar a capacidade do modelo em administrar fatores como tempo, risco e custo de um modo eficiente.

Segundo Rogar (2012), a Zara não trabalha com estoque nem com coleção pré-definida. É o feedback constante das vendas nas lojas que define o que continuará sendo produzido nas fábricas. Dessa forma, as tendências que têm grande retorno em vendas continuam nas araras. Rogar (2012) assinala ainda que as lojas da Zara são abastecidas duas vezes por semana. Para isso, 260 estilistas trabalham em um ritmo frenético na sede da empresa em Arteixo, na Espanha, onde a marca possui onze fábricas.

Com o objetivo de conquistar um público diversificado, as redes de fast fashion também investem em coleções de caráter semi-exclusivo, além das linhas básicas voltadas ao consumo de massa. Os produtos diferenciados, direcionados ao consumidor que se preocupa com a marca e a inovação estética da roupa, são produzidos em larga escala a partir dos anseios do mercado. Delgado (2011) informa que a distribuição desses artigos se dá de forma pulverizada para o mundo todo, dando a impressão de que há uma produção pequena por modelo, ou a sensação de uma semi-exclusividade. A Zara é uma empresa do segmento que se utiliza dessa estratégia comercial.

Na tentativa de explicar as razões do sucesso do fast fashion, Cietta (2010) aponta a capacidade deste sistema em gerenciar de uma forma eficiente os problemas relacionados aos riscos. 
A gestão do risco tornou-se complexa pelo fato de que o grau de risco de uma determinada produção varia nas diversas fases produtivas: ele é mais arriscado quanto menor e altamente fragmentada é a informação. É menos arriscado quando for alto o nível de informação, ou quando se estiver bem próximo do momento de consumo. A política comercial das empresas de fast fashion é fortemente orientada a um segmento de consumidores de forma específica. A escolha dos tamanhos, do estilo e do canal de distribuição é feita de maneira muito consciente, inclusive, em relação à minimização de riscos e de custos (CIETTA, 2010: 36).

Em seguida, o autor analisa o aspecto do sistema criativo no contexto da moda rápida. Para Cietta (2010), este é outro ponto bem administrado pelas empresas do segmento, já que sabem operar de modo duplo - inovando e ao mesmo tempo incorporando as últimas tendências de consumo.

Outro aspecto apontado por Cietta (2010) para compreender o sucesso do fast fashion está relacionado à modernização da distribuição vista nos últimos dez a 15 anos no mundo. Segundo o autor, na década de 1990, a competição entre as empresas se deu principalmente no terreno da distribuição e da logística, muito mais que no setor produtivo. "Graças à globalização, as fontes de fornecimento de baixo custo puderam ser encontradas (...) Esta mudança marcou o início de um novo modelo de negócios" (CIETTA, 2010: 48).

Em um estudo sobre o fast fashion italiano, Cietta (2010) indica as características dessas empresas e o seu modo de funcionamento. O fast fashion italiano soube aproveitar o fluxo de informações de seu sistema produtivo, sejam as informações sobre o andamento das vendas, os dados do estoque ou os produtos remanescentes de fim de estação. Assim, a otimização da logística para o modelo italiano tornou possível uma gestão unificada do sistema de fornecimento de matérias-primas, de produção, de gestão de produtos nos pontos de venda, contribuindo para a redução do risco inerente ao ciclo normal de produção e vendas de roupas. $O$ sistema italiano também investiu em uma política de comunicação sobre os pontos de venda, de modo a apresentá-los de forma coerente com a imagem dos produtos, começando pelo layout e decoração das lojas, além dos materiais informativos, composição de vitrines e promoções periódicas.

\section{A construção da identidade de marca e o sistema fast fashion: uma análise desta relação}

Para compreender a questão da identidade de marca no contexto fast fashion, é importante trazer alguns conceitos a respeito de identidade de marca, para posteriormente analisar tais diretrizes no segmento fast fashion.

De acordo com Guidi (2005), a marca dá personalidade ao produto e também lhe confere uma história, pois funciona como um instrumento de diferenciação e segmentação no mercado, sinalizando diferentes classes sociais, níveis de status e estilos de vida. Por isso, a marca é considerada um elemento de distinção entre os concorrentes, já que transmite a imagem e a mensagem de uma empresa.

Para Silva (2007), a identidade de uma marca é a tradução de seus aspectos imateriais, tais como "sua filosofia, coeficiente de qualidade, status, valores agregados, entre outros; e materiais como preço, funcionalidade, design".

$\mathrm{Na}$ análise da autora, as características imateriais mostram-se mais relevantes na construção da identidade de uma marca, já que os aspectos materiais podem ser mais facilmente compartilhados e são passíveis de serem superados pelos concorrentes.

Nesse sentido, Silva (2007) defende que a identidade de uma marca não nasce por acaso, ao contrário, a identidade é construída. O processo de construção da identidade de uma marca é um modo de organizar as significações que a mesma produz, destacando-a dos concorrentes e funcionando como um modo de reafirmar sua personalidade, sua filosofia e valores. Porém, a autora considera que se essas significações estiverem isoladas, não exercerão influência sobre os consumidores. A eficácia dessa construção está em conectá-la à divulgação. Por meio da divulgação, se dará a aceitação social fundamental para construir e solidificar a identidade de uma marca.

Já Calkins (2006) ressalta que uma marca é um conjunto de associações vinculadas a um nome, 
sinal ou símbolo, relacionados a um produto ou serviço. "A diferença entre um nome e uma marca é que um nome não tem associações; é simplesmente um nome. Um nome torna-se uma marca quando as pessoas o vinculam a outras coisas. Uma marca é bem parecida com a reputação" (CALKINS, 2006: $1)$.

Dessa forma, a partir dos conceitos expostos sobre identidade de marca, a análise passa a se concentrar em compreender de que modo tais diretrizes encontram-se implicadas dentro do sistema fast fashion.

Na visão de Erner (2005), o circuito curto ou o fast fashion pode ser definido como uma maneira heterodoxa de pensar a moda, que privilegia as tendências em prejuízo da criatividade.

Se a primeira preocupação das grandes maisons de costura é criar uma moda original, o circuito curto se singulariza, ao contrário, pela obsessão oposta: produzir o mais tarde possível para fazê-lo como os demais e não errar a tendência. Portanto, o conjunto desse sistema se baseia na reatividade (ERNER, 2005: 147).

Para Erner (2005), o modelo do fast fashion nada tem de original, já que apenas aprimorou um sistema que já existia em Paris, no bairro do Sentier. E assim como no Sentier, assegura o autor, as empresas da moda rápida baseiam suas criações nas tendências e nas marcas que fazem sucesso, copiando de maneira mais ou menos literal os modelos de outras empresas.

Esse método permite produzir a posteriori roupas que correspondem às tendências do momento. Misturando cerca de dois terços de básicos e um terço de produtos de 'moda', essas empresas podem se permitir lançar sua produção um trimestre antes do começo da estação. Nessa época, qualquer profissional saberá determinar as tendências do momento (...) Substancialmente, esse sistema dispensa a criação de uma marca ou de uma moda; porém, permite ir atrás do sucesso (ERNER, 2005: 148).

No apontamento de Delgado (2011), o sistema fast fashion não é bem-visto pelo mercado criador de moda. As empresas da moda rápida são criticadas pelos seus processos criativos, que resultam em roupas similares aos modelos criados pelas equipes de estilo de marcas renomadas.

Já Cietta (2010) compreende que o modelo fast fashion não é somente uma atividade de cópia, mas um "complexo de estratégias que objetivam organizar, em um setor no qual o tempo é escasso, uma variável de escolha, velocidade e qualidade, amplitude de variedades e produtos pensados para públicos específicos" (CIETTA, 2010: 25). De acordo com o autor, o sistema da moda rápida se destaca porque não abriga uma rígida divisão entre fases e funções empresariais, ao contrário, apresenta novos modelos de gestão para cada etapa.

Por apresentar capacidade de minimizar riscos e custos de uma coleção não apreciada pelo mercado, de otimizar a gestão do processo criativo e de tornar flexível a cadeia produtiva, o fast fashion tornou-se um modelo de sucesso (CIETTA, 2010: 24).

No que diz respeito à autonomia estilística, Cietta (2010) afirma que as empresas do segmento têm como objetivo definir uma coleção na qual prevaleçam os produtos de maior sucesso de acordo com as tendências. Entende-se por coleção, neste caso, um grupo de produtos que definam um estilo específico e que sejam coerentes entre si.

No entanto, Cietta (2010) admite que as empresas do fast fashion não produzem roupas de cunho autoral, com estética inovadora, em virtude da preocupação com o sucesso das vendas.

A exigência de uma coleção com a melhor eficácia de vendas continua a levar as empresas de moda rápida a se inspirarem nos estilistas e nas empresas trend setter. A possibilidade de comercialização deve considerar certo estilo empresarial com um target de mercado preciso e um determinado nível de preço a ser atingido (CIETTA, 2010: 39). 
Nesse sentido, analisando as empresas do fast fashion e o conceito de identidade de marca trazido por Silva (2007), é possível concluir que essas empresas, em especial no que diz respeito às suas características tangíveis, tais como preço, funcionalidade, configuração formal e matérias-primas, têm firmado uma imagem associada ao baixo nível qualitativo de seus produtos. Porém, o fator preço mostra-se como um diferencial competitivo para as marcas da moda rápida.

Sobre o design das coleções do fast fashion, seus produtos apresentam baixo grau de diferenciação em relação às empresas que estão no mercado há mais tempo, visto que seus artigos apresentam bastante similaridade às observadas em desfiles e feiras do setor.

Com relação à apreciação das características intangíveis da marca, apontadas por Silva (2007) como sendo a filosofia, o status proporcionado pela marca, a personalidade e os valores, as empresas do fast fashion têm grandes desafios a transpor. A começar pelo modelo produtivo adotado, que funciona à base de terceirizações da produção por intermédio de oficinas que desrespeitam a legislação trabalhista, explorando a mão de obra de seus empregados.

Para Bonorino (2012), a médio e longo prazo, as redes de fast fashion sofrerão quedas em seus faturamentos, já que este modelo de negócios está se esgotando e não representa mais uma tendência entre os consumidores.

Já está mais do que na hora de começarmos a desacelerar o consumo de moda sem muita durabilidade e design 'inspirado/colado' nas marcas referência do mercado (...) É fato que o consumo de fast fashion serviu para alavancar a empregabilidade em países pobres, porém essas indústrias precisam começar a se preparar para produzir, pelo menos, produtos com mais qualidade, a preços razoáveis, para atender às novas expectativas do consumidor que não pretende mais compartilhar desse processo de compras descartável. (BONORINO, 2012).

Em uma perspectiva para o futuro, a autora acredita que o fast fashion será substituído pelo slow fashion, e essa mudança vai exigir um esforço maior das marcas no projeto e produção de suas coleções. Dessa forma, Bonorino (2012) defende que cada detalhe que envolver o desenvolvimento do produto e a sua apresentação vai ser valorizado pelos consumidores, que estarão avaliando se realmente precisarão de mais uma blusa quando estiverem olhando para várias em uma arara de loja.

\section{CONSIDERAÇÕES FINAIS}

A partir do que foi exposto nesse artigo, é possível constatar que as questões de identidade de marca dentro do contexto fast fashion apontam para um sistema que agrupa inúmeras associações negativas atreladas à sua imagem, sobretudo quando são postos em análise os aspectos intangíveis da identidade de uma marca.

Retomando um dos conceitos de identidade de marca, Silva (2007) explica que tal como as pessoas, as marcas têm identidades próprias, isto é, carregam consigo "caráter e personalidade ligados à sua história e aos seus valores fundamentais".

Nesse sentido, como explicar a aceitação das marcas de fast fashion por parte do público em diversos países, se a imagem dessas empresas está ligada a atributos que desrespeitam as normas internacionais de Direitos Humanos e as regras de uma conduta ética para competir no mercado?

A resposta para tal indagação talvez possa ser respondida, em parte, pela constatação de Delgado (2008), quando explica que a maioria do público não chega a tomar conhecimento da concorrência entre as empresas no âmbito de seus processos produtivos e, sobretudo, no que diz respeito às suspeitas de atividade de cópia por parte do fast fashion. "A maioria dos clientes não chega a tomar conhecimento desta concorrência, ficando mais atentos ao estilo e ao preço das peças que irão usar do que aos 'bastidores' das empresas de moda" (DELGADO, 2011: 8).

Já Lipovetsky (2004) demonstra em seus estudos que a sociedade atual vive sob novos arranjos, em que o universo do consumo parece ser entendido como um sonho jubiloso, justificando assim o sucesso das redes de fast fashion na atualidade. 
Nasce uma nova cultura hedonista e psicologista que incita à satisfação imediata das necessidades, estimula a urgência dos prazeres, enaltece o florescimento pessoal (...) Consumir sem esperar; viajar; divertir-se; não renunciar a nada: as políticas do futuro radiante foram sucedidas pelo consumo como promessa de um futuro eufórico (LIPOVETSKY, 2004: 61).

Segundo Cietta (2010), a moda rápida sempre foi identificada como um segmento de mercado que produz produtos de baixo nível qualitativo, não comparável às características do sistema prêt-à-porter. Porém, o autor explica que atualmente os dois mundos estão se sobrepondo, ou seja, os consumidores passaram a adquirir artigos de marcas de luxo e produtos do fast fashion, coordenando as peças de acordo com o seu estilo, e não mais como forma de adquirir status social por meio dos produtos que veste.

Já sobre a compatibilidade do modelo fast fashion com a construção de uma identidade de marca, é necessário recorrer ao conceito apontado por Silva (2007).

A identidade de uma marca é a tradução de seus aspectos imateriais, tais como sua filosofia, coeficiente de qualidade, status, valores agregados, e materiais como preço, funcionalidade e design, que a representam e a diferenciam das demais (SILVA, 2007: 24).

Aprofundando o raciocínio, a autora explica que a identidade de uma marca só terá significado para o público se os aspectos que a compõem forem divulgados, já que este é o processo pelo qual se dá a aceitação social para construir e consolidar a identidade de marca no mercado.

Segundo Cietta (2010), as empresas do fast fashion se preocupam em seguir parâmetros próprios para estabelecer vínculos com seus públicos, visando aumentar o reconhecimento da marca junto aos consumidores, ganhar espaço no mercado, nas mídias e na opinião de líderes. Assim, a aposta das empresas da moda rápida é a de não investir em ferramentas tradicionais de divulgação como desfiles e grandes verbas em publicidade, como fazem as marcas de luxo. Mesmo assim, "a atenção à coerência na própria comunicação é uma das características principais das empresas de fast fashion" (CIETTA, 2010: 41).

A Zara é um exemplo de empresa do segmento que tem se mostrado capaz de construir uma identidade de marca, já que investe na comunicação com seus consumidores, tratando o assunto como um diferencial competitivo, como demonstra Sologa (2007) em sua pesquisa.

Um dos ingredientes do crescimento exorbitante da Zara é seu modelo de comunicação. O diretor de comunicação da empresa, Jesús Echevarría, responde diretamente à direção da companhia, assim como os outros seis diretores do grupo (...) As lojas da marca são consideradas eixos centrais de toda a comunicação com seus consumidores (...) Nos pontos de venda, quando dois ou três clientes perguntam a um funcionário sobre uma peça que não encontraram, o mesmo se comunica à gerente da loja, que informa à central de produção sobre o pedido. Provavelmente, o cliente poderá encontrar a peça ou uma similar no prazo de 48 horas no caso do consumidor da Espanha, e em 72 horas em uma loja Zara localizada em território estrangeiro (...) Nas lojas, os produtos são organizados de forma a não se apresentarem de modo acumulado em grandes quantidades, assim como acontece nas lojas de produtos de luxo. Existem espaços vazios entre as coleções para que o consumidor possa obter uma visão de conjunto das peças e da própria loja (...) A empresa mantém lojas-piloto em tamanho real em sua sede na cidade de Arteixo, na Espanha, onde cria duas vezes ao ano, e troca a cada duas semanas, versões distintas do interior de suas lojas. Posteriormente, fotografias digitais das lojas-modelo são enviadas para os pontos de venda da rede, para que a decoração seja reproduzida exatamente no mesmo formato, desde as vitrines até a disposição das roupas. (SOLOGA, 2007: 55).

Ainda sobre o processo de comunicação da Zara, a autora aponta que não somente o 
consumidor é visto como o foco das atenções da marca. Públicos internos, como seus funcionários, também ganham espaço e ferramentas próprias de comunicação.

A centralidade no cliente não significa que os demais públicos não sejam importantes. Para seus funcionários, desenvolve distintas ferramentas, começando pelo el mentoring, para formar empregados e promover internamente as suas equipes: $44 \%$ dos novos postos do Grupo Inditex são cobertos por meio de promoções internas. Porém, a principal ferramenta de comunicação interna do grupo é a revista IN, desenvolvida para seus funcionários. A revista é editada em papel, em cinco idiomas além do espanhol: inglês, francês, português, alemão e italiano. (SOLOGA, 2007: 56).

Dessa forma, entende-se que o processo da Zara em estabelecer um vínculo duradouro com seus diversos públicos vem sendo realizado de forma planejada e sistemática, portanto, a construção de uma identidade de marca está sendo realizada e se insere dentro do próprio desenvolvimento da companhia. A partir desse exemplo e das análises anteriores, pode-se concluir que, embora a manutenção de códigos estilísticos próprios pareça difícil, uma empresa do sistema fast fashion apresenta potencial para construir e solidificar sua identidade de marca no mercado de moda.

\section{REFERÊNCIAS}

BONORINO, Evelyn. Fast Fashion: Mocinho ou Vilão? In: Evelyn B, 2012.

Disponível em: http://evelynb.com.br/informacoes/direcoes/fast_fashion.html. Acesso em 08/01/12.

BONORINO, Evelyn. Fast Fashion x Slow Fashion. In: Evelyn B, 2012.

Disponível em: http://www.evelynb.com.br/informacoes/direcoes/fast_slow.html. Acesso em: 10/01/2012.

CAETANO, Carolina Carpinelli e HELD, Maria Silvia Barros. O fast fashion e a estratégia do crossbranding. In: 70 Colóquio de Moda, 2011, Maringá. Anais. 1-11.

CIETTA, Enrico. A revolução do fast fashion. Estratégias e modelos organizativos para competir nas indústrias híbridas. São Paulo: Estação das Letras e Cores, 2010.

DELGADO, Daniela. Fast fashion: estratégia para conquista do mercado globalizado. In: Revista ModaPalavra e-Periódico, do Centro de Artes da Universidade do Estado de Santa Catarina, ano 1, n.2, 2008.

ERNER, Guillaume. Vítimas da moda? Como a criamos, por que a seguimos. São Paulo: Senac, 2005.

GUIDI, Maria C. Pontes. Marca, identidade e comunicação na moda. Disponível em: http://www. antennaweb.com.br/edicao1/artigos/artigo_carolina.htm. Acesso em: 15/02/2012.

GRUMBACH, Didier. Histórias da moda. São Paulo: Cosac Naify, 2009.

LIPOVETSKY, Gilles. O Império do efêmero: a moda e seu destino nas sociedades modernas. São Paulo: Companhia das Letras, 1989.

LIPOVETSKY, Gilles. Os tempos hipermodernos. São Paulo: Barcarolla, 2004.

MCCRACKEN, Grant. Cultura \& consumo. Novas abordagens ao caráter simbólico dos bens e das atividades de consumo. Rio de Janeiro: Mauad, 2003.

ROGAR, Silvia. Conheça por dentro uma das fábricas da Zara na Espanha. Disponível em: http:// vogue.globo.com/moda/news/conheca-por-dentro-uma-das-fabricas-da-zara-na-espanha. Acesso 
em: 05/06/2012.

ROGAR, Silvia. Zara city: por dentro da gigante do fast fashion. Disponível em: http://vogue.globo. com/moda/news/por-dentro-da-zara. Acesso em: 05/06/2012.

SILVA, Vivianne Cabral. Construção de identidade de marca, fotografia de moda e erotismo: As campanhas Sisley. (Dissertação). Mestrado em Cultura Visual. Faculdade de Artes Visuais da Universidade Federal de Goiás. Goiânia, 2007.

SOLOGA, Paloma Díaz. El valor de la comunicación. Como gestionar marcas de moda. Madrid: Cie Inversiones Editoriales Dossat, 2007.

TYBOUT, Alice M. e CALKINS, Tim. Branding: fundamentos, estratégias e alavancagem de marcas: implementação, modelagem e checklists: experiências de líderes de mercado. São Paulo: Atlas, 2006. 